\title{
Los parámetros espermáticos funcionales como factor pronóstico en ICSI: Experiencia de la ciudad de Medellín
}

\section{Functional Seminal Parameters as a Prognostic Factor in ICSI: Medellín City Experience}

\author{
Luisa F. Calderón-Mendoza ${ }^{1} \quad$ Lucero Castrillón López ${ }^{1}$ Carlos Felipe Vélez Giraldo ${ }^{1}$ \\ Verónica Isaza Álvarez ${ }^{1}$ Walter D. Cardona-Maya ${ }^{20}$ \\ ${ }^{1}$ Centro de Medicina Reproductiva CONCEVIDAS, Medellín, Colombia \\ 2 Grupo de Reproducción, Departamento de Microbiología y Parasitología, \\ Facultad de Medicina, Universidad de Antioquia, Medellín, Colombia \\ Address for correspondence Walter D. Cardona-Maya, Bact., MSc., \\ PhD., Grupo Reproducción, Departamento de Microbiología y \\ Parasitología, Facultad de Medicina, Universidad de Antioquia, \\ Medellín, Colombia (e-mail: wdario.cardona@udea.edu.co).
}

Urol Colomb 2019;28:313-319.

\section{Resumen}

\section{Palabras claves}

- espermatozoide

- ICSI

- inyección intracitoplasmática de espermatozoides

- pruebas funcionales

- fertilidad

- espermograma.
Introducción La infertilidad por factor masculino afecta al $30 \%$ de las parejas infértiles y la evaluación seminal es crítica en las determinaciones que conllevan a un posible tratamiento con el fin de tener un resultado exitoso.

Objetivo El objetivo de este estudio fue evaluar la relación que existe entre los parámetros seminales convencionales y funcionales, con las tasas de fecundación, desarrollo embrionario y embarazo obtenidas después de inyección intracitoplasmática de espermatozoides (ICSI).

Métodos 36 muestras seminales de parejas que se sometieron a ICSI (18 usando oocitos propios y 18 de donante), fueron evaluadas de manera convencional, posteriormente se seleccionaron los espermatozoides, se realizó ICSI y una alícuota se utilizó para cuantificar las siguientes pruebas funcionales: potencial de membrana mitocondrial, integridad de la membrana, detección de especies reactivas de oxígeno e índice de fragmentación del ADN.

Resultados No se encontraron diferencias significativas en cuanto a los parámetros convencionales y funcionales en los dos grupos, como tampoco se encontró una relación significativa entre los parámetros evaluados y los resultados de ICSI. Sólo se observó que la tasa de embarazo fue mayor en el grupo de oocitos donados $(\mathrm{p}<0,0001)$.

Conclusiones Los datos obtenidos en este estudio sugieren que no existe correlación entre los parámetros evaluados y los resultados de ICSI. Eso se debe probablemente, a que la selección de los espermatozoides tanto por gradientes de densidad como la posterior selección durante el procedimiento del ICSI, tiene un bajo poder predictivo sumado a la capacidad que tiene el oocito de reparar los daños presentes en el espermatozoide. received

November 26, 2018

accepted

March 26, 2019
DOI https://doi.org/

$10.1055 / \mathrm{s}-0039-1688463$.

ISSN 0120-789X.

e ISSN 2027-0119.
Copyright ( 2019 , Sociedad Colombiana License terms de Urología. Publicado por Thieme Revinter Publicações Ltda., Rio de Janeiro, Brazil. Todos los derechos reservados.

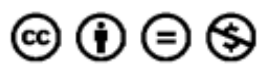




\begin{abstract}
Background Male infertility affects $30 \%$ of infertile couples and seminal evaluation is critical in the determinations that lead to a possible treatment in order to have a successful outcome.

Objective The objective of this study was to evaluate the relationship between conventional and functional seminal parameters, with the rates of fertilization, embryo development and pregnancy obtained after ICSI.

Methods 36 semen samples of couples that underwent ICSI (18 using own oocytes and 18 from donors) were conventionally evaluated, spermatozoa were subsequently selected, ICSI was performed and an aliquot was used to quantify the following functional tests: mitochondrial membrane potential, membrane integrity, reactive oxygen species detection and DNA fragmentation index.

Results There were no significant differences in the conventional and functional

Keywords

- spermatozoa

- ICSI

- intracytoplasmic sperm injection

- functional test

- fertility

- semen analysis parameters in the two groups, nor was there a significant relationship between the parameters evaluated and the ICSI results. It was only observed that the pregnancy rate was higher in the group of donated oocytes ( $<<0.0001)$.

Conclusions The data obtained in this study suggest that there is no correlation between the parameters evaluated and the ICSI outcome. This is probably because the selection of spermatozoa by density gradients in addition to the subsequent selection during ICSI has a low predictive power and also the ability of the oocyte to repair the damage present in the spermatozoa.
\end{abstract}

\section{Introducción}

La infertilidad es una enfermedad que afecta a más de 70 millones de parejas en edad reproductiva en el mundo y se calcula que aproximadamente el $30 \%$ de los casos se deben exclusivamente al factor masculino. ${ }^{1}$ Con el fin de determinar si el factor masculino está involucrado en la imposibilidad de conseguir un embarazo y estimar la gravedad del problema, se realiza generalmente un análisis de la muestra seminal o espermograma ${ }^{2}$ el cual constituye una herramienta valiosa para el médico especialista y hasta la fecha es el único examen que permite valorar el estado fértil de un individuo.

La Organización Mundial de la Salud (OMS) desde la década de los 80, ha realizado importantes esfuerzos con el fin de propiciar que las metodologías usadas durante el análisis seminal estén estandarizadas en los laboratorios en todo el mundo ${ }^{3}$; sin embargo, el uso de esos parámetros no predice con exactitud y precisión la capacidad fértil de un hombre, ${ }^{4} \mathrm{ni}$ los resultados de un tratamiento de reproducción asistida, ${ }^{5}$ lo cual es debido probablemente a que existen muchos factores que contribuyen a la capacidad que tiene un espermatozoide para interactuar con un oocito y generar un cigoto.

Es importante recalcar que durante la estimación de los parámetros seminales mediante el espermograma, no se valoran todos los aspectos de la función testicular, ni se proporciona evidencia del origen etiológico y fisiológico de algún trastorno, y por esa razón surgieron las pruebas funcionales espermáticas, las cuales son un conjunto de estudios especializados que evalúan aspectos funcionales de los espermatozoides y parecen estar más relacionadas con el potencial fértil del hombre. ${ }^{6}$ Así mismo, ofrecen más información acerca de la naturaleza, origen y causa de la infertilidad, ${ }^{7}$ además de estar asociadas con los resultados de la fertilización in vitro (FIV).

De otro lado, la inyección intracitoplasmática de espermatozoides (ICSI), el procedimiento más ampliamente utilizado en el mundo para fecundar oocitos, ha posibilitado la fecundación independientemente de algunas características espermáticas como la morfología y la movilidad, además ha permitido obtener información relevante sobre el proceso de la fecundación, específicamente acerca de la activación del oocito y la liberación de calcio. ${ }^{8}$ La finalidad de esa técnica en un principio, fue tratar el factor masculino severo, pero en la actualidad, tiene indicaciones de todo tipo incluyendo femeninas y, por esa razón, en muchos centros de medicina reproductiva sólo utilizan y dependen de la ICSI.

A la fecha, las tasas de embarazo de los tratamientos de alta complejidad siguen siendo consideradas como subóptimas, lo cual puede ser el resultado del diagnóstico reducido y poco informativo de la calidad de los espermatozoides empleados en esos procedimientos. Por lo tanto, el objetivo de este estudio, fue evaluar la relación que existe entre los parámetros seminales convencionales y funcionales, con las tasas de fecundación, desarrollo embrionario y embarazo obtenidas por ICSI.

\section{Métodos}

\section{Pacientes}

Este estudio prospectivo se realizó entre febrero de 2016 y julio de 2017 en el Centro de Medicina Reproductiva Concevidas y el Grupo Reproducción, Facultad de Medicina, 
de la Universidad de Antioquia. Se obtuvo el consentimiento informado por escrito de todos los participantes y el estudio fue aprobado por el Comité de Bioética adscrito a la Facultad de Medicina de la Universidad de Antioquia.

Se incluyeron 36 parejas, de las cuales 18 usaron sus propios oocitos y 18 recibieron oocitos donados. Sólo se incluyeron muestras de semen frescas y se excluyeron aquellas con oligozoospermia severa ( $<1$ millón de espermatozoides $/ \mathrm{mL}$ ). La donación de oocitos es anónima y se buscaron voluntarias jóvenes (18-27 años) según las características fenotípicas de las receptoras. Adicionalmente, se realizaron exámenes serológicos (hemoclasificación, VIH, antígeno de Hepatitis B, anticuerpos contra Hepatitis C y citomegalovirus), además de un cariotipo de acuerdo al artículo 13 de la resolución 3199 de 1998, exigida por el Instituto Nacional de Vigilancia de Medicamentos y Alimentos (INVIMA) en Colombia.

\section{Estimulación ovárica}

La estimulación ovárica de pacientes y donantes comenzó a partir del día 1, 2 o 3 del ciclo menstrual con una ecografía transvaginal con el fin de verificar la quiescencia ovárica. Se inició la inducción de la ovulación con una dosis de FSH (GONAL-f®, Merck, Darmstadt, Alemania) o con una dosis de FHS/LH (Menopur $®$, Ferring Pharmaceuticals, Saint-Prex, Suiza o Pergoveris® Merck Serono, Modugno, Italia), que varía desde 225 UI hasta $450 \mathrm{IU} /$ día dependiendo del caso. Al sexto día de estimulación, se aplicó una dosis de antagonista de la GnRH (Cetrotide ${ }^{\circledR}$ Merck Frankfurt, Alemania) si habían folículos entre 14-15 mm. Cuando se encontró una cohorte folicular de entre 19 y $20 \mathrm{~mm}$, se realizó el disparo de la ovulación con un agonista de la GnRh (Gonapeptyl ® Daily, Ferring Pharmaceuticals, Kiel, Alemania) y 36 horas después se procedió a la aspiración folicular.

Posteriormente, las pacientes con oocitos propios comenzaron un soporte de progesterona por dos vías: oral con 400mg de progesterona natural cada noche (Utrogestan, Biopas Laboratories, Bogotá, Colombia) y vaginal con progesterona en gel al $8 \%$ todas las mañanas (Crinone ${ }^{\circledR}$, Central Pharma, Reino Unido) hasta la determinación de la prueba de embarazo si era negativa o durante los tres primeros meses de embarazo si era positiva. De otro lado, las mujeres receptoras recibieron preparación endometrial previa a la transferencia de embriones con valerato de estradiol (Progynova ${ }^{\circledR}$ Bayer group, Alemania) por vía oral con una dosis de $6 \mathrm{mg} /$ día durante 10 a 15 días. Posteriormente, se realizo una ecografía transvaginal para determinar el grosor y la apariencia endometrial, además de una cuantificación sérica de estradiol. El día de la aspiración folicular de la donante se comenzó con soporte de progesterona de la misma forma que para las mujeres que usaron oocitos propios.

\section{Recolección y preparación de la muestra de semen}

Las muestras de semen fueron recolectadas por masturbación en un contenedor estéril después de aproximadamente 2 a 5 días de abstinencia sexual. Luego de la licuefacción, aproximadamente entre 45 minutos y 1 hora, se realizó la evaluación de los parámetros seminales convencionales siguiendo los lineamientos establecidos en el Manual para el procesamiento de semen humano de la OMS (2010). ${ }^{7}$ Una vez realizado el espermograma, la muestra fue preparada por gradientes de densidad de 90 y 45\% Sperm Grad (Vitrolife, Suecia) y el sedimento recuperado fue lavado y resuspendido con medio de cultivo All Grad Wash (Life Global, Estados Unidos de América), con el fin de realizar el procedimeinto de ICSI, determinar la movilidad y morfología espermática post selección y cuantificar las pruebas funcionales espermáticas.

\section{Pruebas funcionales}

Los análisis de citometría de flujo se llevaron a cabo en el citómetro de flujo Epics XL (Becton Dickinson, CA, EUA), con una longitud de onda de excitación de $488 \mathrm{~nm}$ suministrada por un láser de argón. Las mediciones de dispersión frontal (forward scatter) y de dispersión lateral (side scatter) se utilizaron para seleccionar la población de espermatozoides a analizar y excluir los detritos y agregados que producen efectos indeseados en la fluorescencia general. Un total de 10.000 eventos fueron obtenidos por prueba y todos los datos fueron analizados posteriormente usando el programa FlowJo 7.6.2 (FlowJo LLC, OR, Estados Unidos de América).

\section{Potencial de membrana mitocondrial $\left(\Psi_{m}\right)$}

El $\Psi_{m}$ se evaluó usando la tinción con yoduro de 3,3'-dihexiloxacarbocianina (DiOC6, ${ }^{3}$ Molecular Probes Inc., Países Bajos) un colorante lipófilo, catiónico y selectivo para la mitocondria de células vivas. El yoduro de propidio (IP, Molecular Probes Inc., Países Bajos), se utilizó como contratinción para discriminar células necróticas/muertas. ${ }^{9}$ Brevemente, $2 \times 10^{6}$ de espermatozoides se incubaron en $300 \mu \mathrm{L}$ de buffer fosfato salino (PBS, pH 7,4, Gibco $囚, \mathrm{NY}$, Estados Unidos de América) con DiOC6 (concentración final de $10 \mathrm{nM}$ ) y con IP (concentración final de $12 \mu \mathrm{M}$ ) protegidos de la luz $\left(30 \mathrm{~min}, \mathrm{a} 25^{\circ} \mathrm{C}\right.$ ). A continuación, los espermatozoides se lavaron en PBS ( $180 \mathrm{~g}, 5 \mathrm{~min}$ ), el botón fue resuspendido en PBS y se llevó al citómetro de flujo. Los datos fueron analizados como el porcentaje de espermatozoides vivos con alto y bajo $\Delta \Psi \mathrm{m}$.

\section{Producción intracelular de especies reactivas del oxígeno (ERO) y del nitrógeno (ERN)}

Los niveles intracelulares de ERO y ERN (específicamente $\mathrm{H}_{2} \mathrm{O}_{2}$, HO-, ROO- y ONOO-), fueron evaluados utilizando 2', 7'-di-acetato de di-cloro di-hidrofluoresceina (DCFH-DA; Sigma-Aldrich, St Louis, MO, Estados Unidos de América, concentración final de $1 \mu \mathrm{M}$ ). Después de la escisión de los grupos acetato por las esterasas intracelulares, el DCFH oxida selectivamente por las ERO y ERN hasta 2', 7'diclorofluoresceína (DCF) el cual fluoresce en verde. ${ }^{10} \mathrm{El} \mathrm{IP}$ se utilizó para excluir las células necróticas/muertas. La suspensión de células se incubó protegida de la luz (30 min, a $25^{\circ} \mathrm{C}$ ), se lavó tres veces con PBS $(180 \mathrm{~g}, 5 \mathrm{~min})$ y el botón fue resuspendido en PBS antes de ser analizado por citometría de flujo. Los resultados se expresaron como el porcentaje de espermatozoides positivos para DCF: espermatozoides vivos que exhiben la respuesta verde fluorescente (espermatozoides vivos produciendo ERO y ERN). 


\section{Evaluación de la integridad de la membrana plasmática}

Se utilizó el estuche comercial LIVE/DEAD® Sperm (Molecular Probes Inc., Países Bajos), para evaluar la integridad de la membrana plasmática, el cual permite discriminar tres poblaciones de espermatozoides. Brevemente, $2 \times 10^{6}$ de espermatozoides se incubaron en $300 \mu \mathrm{L}$ de PBS con SYBR14 y con IP (fluorescencia verde y roja, concentración final de $1 \mathrm{mMy} 12 \mathrm{mM}$, respectivamente) protegidos de la luz (30 min, a $25^{\circ} \mathrm{C}$ ), se lavaron con PBS (180 g, $5 \mathrm{~min}$ ) y se resuspendieron en PBS antes del análisis por citometría de flujo. Los datos se expresaron como el porcentaje de espermatozoides viables (células de la membrana plasmática intacta, positivos a SYBR14 y negativas para PI), células necróticas/muertas (positivas para IP) o espermatozoides moribundos (dobles positivos).

\section{Integridad de la cromatina}

La evaluación de la estructura de la cromatina espermática (SCSA) se utilizó para determinar el índice de fragmentación del ADN espermático (IFA), según lo descrito previamente por Evenson y col., ${ }^{11}$ y adaptado en el Grupo Reproducción. ${ }^{12}$ Brevemente, $400 \mu \mathrm{L}$ de una solución de detergente ácido $(\mathrm{HCl}, \mathrm{NaCl}$, Triton X-100, agua, $\mathrm{pH}: 1,2)$ se añadieron a $5 \times 10^{6}$ de espermatozoides suspendidos en $200 \mu \mathrm{L}$ de buffer TNE (Tris- $\mathrm{HCl}, \mathrm{NaCl}$ y EDTA, pH: 7,4). Después de 30 segundos, los espermatozoides se colorearon con $600 \mu \mathrm{L}$ de naranja de acridina $(6 \mathrm{mg} / \mathrm{mL}$, Sigma-Aldrich, St Louis, MO, EUA). El IFA se calculó con la intensidad media de fluorescencia (IMF) roja en proporción a la fluorescencia total (IMF roja + IMF verde), multiplicado por 100.

\section{Procedimientos de la inyección intracitoplasmática de espermatozoides}

Los oocitos recuperados se inyectaron 4 horas después de la recuperación de los líquidos foliculares y luego se colocaron en gotas de Global Total (Life Global, Estados Unidos de América) bajo parafina liquida equilibrada y se incubaron en una atmósfera de $\mathrm{CO}_{2}$ al $7,5 \%$ humidificada a $37^{\circ} \mathrm{C}$. A las $16-18 \mathrm{~h}$ después de la microinyección, los oocitos fueron evaluados en la etapa de pronúcleo. La fecundación fue calculada como el porcentaje de cigotos resultantes de los oocitos inyectados. La morfología del embrión se evaluó en los días 2 y 3 observando el número, la simetría y la granularidad de las blastómeras, asî como también el tipo y el porcentaje de fragmentación. La transferencia de embriones se realizó el día 3 y los embriones restantes fueron vitrificados cuando su estado morfológico lo permitía. Un embrión adecuado para ser transferido tenía entre 7 y 9 células, menos del 20\% de fragmentación y blastómeras simétricas.

La tasa de desarrollo embrionario se calculó como el número de embriones con el número de células correspondiente sobre el número total de embriones y 15 días después un aumento en la concentración sérica de gonadotropina coriónica $\beta$ hCG indicaba embarazo.

\section{Análisis estadístico}

La distribución de los datos se evaluó mediante las siguientes pruebas de normalidad: D’Agostino-Pearson, Shapiro-Wilk y
Kolmogorov-Smirnov. Las comparaciones se realizaron usando la prueba de Mann-Whitney. Los datos fueron analizados utilizando el programa estadístico Prism 5.0 (GraphPad, San Diego, CA, Estados Unidos de América) y un valor de $\mathrm{p}<0,05$ fue considerado como significativo.

\section{Resultados}

En este trabajo se observó una tasa de embarazo del $27,8 \%$ en pacientes con oocitos propios y del $83,3 \%$ en receptoras ( $\mathrm{p}<0,0001$ ). Como era de esperar, las mujeres del grupo que usó oocitos donados, eran mayores que las que usaron oocitos propios $(39,77 \pm 4,19$ vs $35 \pm 3,69, \mathrm{p}=0,0019) \mathrm{y}$ mayores que las donantes $(39,77 \pm 4,19$ vs 23,61 $\pm 2,74$, $\mathrm{p}<0,0001)$. Respecto a las edades de los hombres, fueron similares en el grupo de oocitos propios $(38 \pm 7,40)$ y el grupo de donantes $(37,27 \pm 822), \mathrm{p}>0,05$.

Tanto en el grupo de los oocitos propios como en el de los donados, se observó un incremento de la movilidad y una disminución de la concentración después de la selección espermática. Sin embargo, ese último en la muestra inicial fue mayor en el grupo de oocitos donados con respecto a los propios ( $\mathrm{p}=0,0470$ ), - Tabla 1 y 2.

Así mismo, no se observaron diferencias significativas en los parámetros funcionales evaluados en los dos grupos (-Figura 1). Finalmente, en la - Tabla 3 se encuentran los valores descriptivos de las tasas de fecundación y de desarrollo embrionario obtenidas en los dos grupos.

Tabla 1 Parámetros seminales convencionales pacientes oocitos propios

\begin{tabular}{|l|l|l|l|}
\hline & Pre-selección & Post-selección & $\begin{array}{l}\text { Valor } \\
\text { de } \boldsymbol{p}\end{array}$ \\
\hline Volumen & $3,9 \pm 1,74$ & & \\
\hline Viabilidad & $\begin{array}{l}63,00 \% \pm \\
7,57 \%\end{array}$ & & \\
\hline Movilidad & $35,00 \% \pm$ & $\begin{array}{l}68,00 \% \pm \\
24,85 \%\end{array}$ & 0,0001 \\
\hline Concentración & $11,30 \%$ & $40,88 \pm$ & 0,0058 \\
& 41,66 & 19,87 & \\
\hline Morfología & $3,00 \% \pm$ & $4,00 \% \pm$ & 0,1072 \\
& $1,79 \%$ & $2,08 \%$ & \\
\hline
\end{tabular}

Tabla 2 Parámetros seminales convencionales pacientes oocitos donados

\begin{tabular}{|l|l|l|l|}
\hline & Pre-selección & Post-selección & $\begin{array}{l}\text { Valor } \\
\text { de } \mathbf{p}\end{array}$ \\
\hline Volumen & $2,5 \pm 0,87$ & & \\
\hline Viabilidad & $\begin{array}{l}66,00 \% \pm \\
4,15 \%\end{array}$ & & \\
\hline Movilidad & $40,00 \% \pm$ & $\begin{array}{l}74,00 \% \pm \\
14,09 \%\end{array}$ & 0,0001 \\
\hline Concentración & $7,16 \%$ & $45,27 \pm$ & 0,0283 \\
& 23,41 & 19,43 & \\
\hline Morfología & $3,00 \% \pm$ & $4,00 \% \pm$ & 0,1423 \\
& $1,85 \%$ & $1,95 \%$ & \\
\hline
\end{tabular}




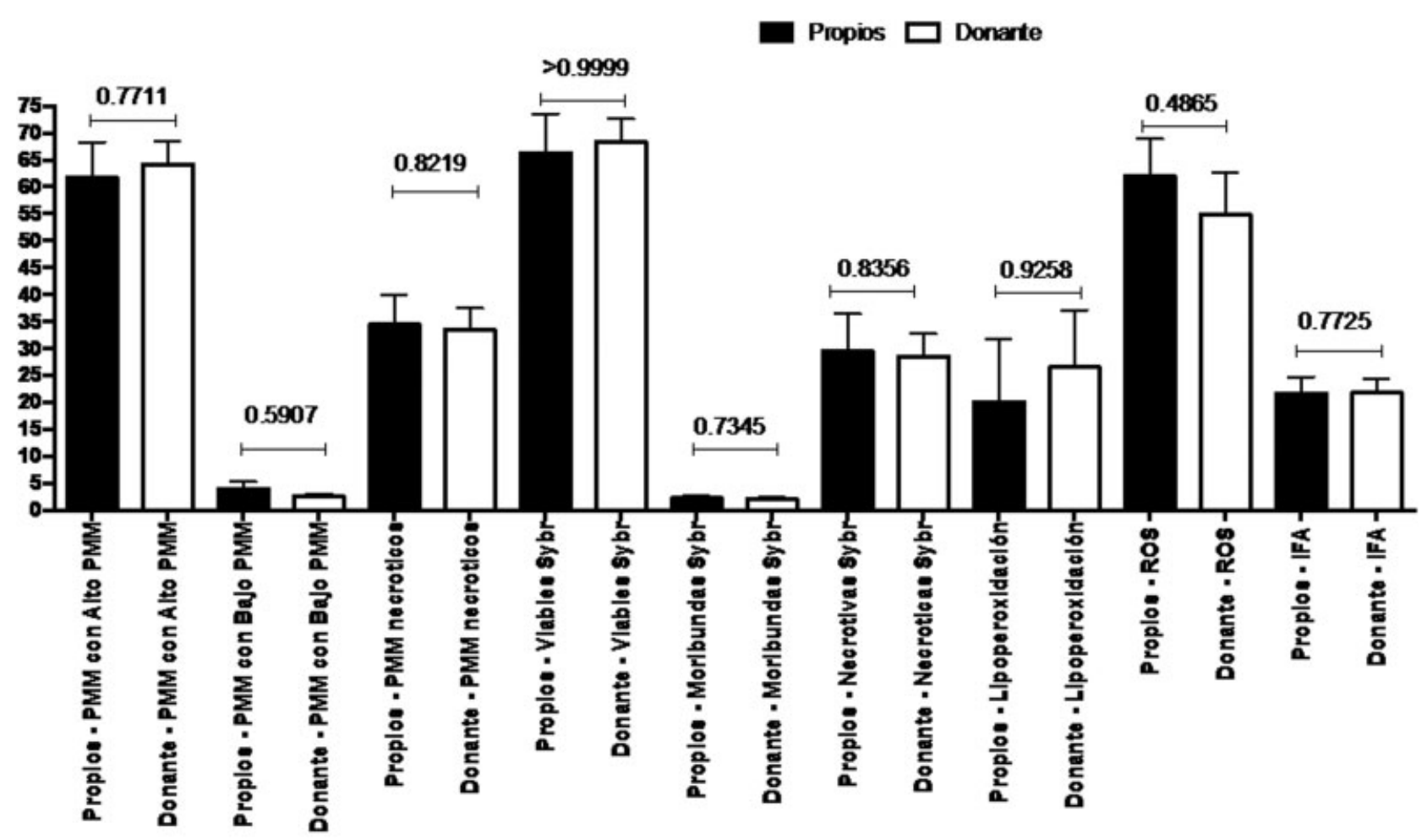

\section{Mann Whitney test}

Fig. 1 Parámetros funcionales evaluados en las muestras seminales seleccionadas, en los grupos de oocitos propios y donados.

Tabla 3 Valores descriptivos obtenidos en la tasa de fecundación y tasa de desarrollo embrionarios

\begin{tabular}{|l|l|l|l|}
\hline & $\begin{array}{l}\text { Oocitos } \\
\text { microinyectados }\end{array}$ & $\begin{array}{l}\text { Tasa de } \\
\text { fecundación }\end{array}$ & $\begin{array}{l}\text { Tasa de } \\
\text { desarrollo } \\
\text { embrionario }\end{array}$ \\
\hline Propios & 181 & $141(78 \%)$ & $98(70 \%)$ \\
\hline Donados & 189 & $160(85 \%)^{\mathrm{a}}$ & $94(59 \%)^{\mathrm{b}}$ \\
\hline Total & 370 & $301(81,5 \%)$ & $192(64,5 \%)$ \\
\hline
\end{tabular}

av propios: $\mathrm{p}=0.27$

bs propios: $\mathrm{p}=0.13$.

\section{Discusión}

Valorar y conocer más acerca del gameto masculino es muy importante, sobre todo cuando se utilizan técnicas de reproducción asistida con el fin de obtener mejores resultados, ya que en la actualidad son ampliamente usadas para lograr un embarazo. En este estudio, se evaluó la relación entre los parámetros seminales tanto convencionales como funcionales y las tasas de fecundación, desarrollo embrionario y embarazo obtenidas después de ICSI, evidenciando que no existe ninguna relación.

Los parámetros convencionales no tienen relación con los resultados de ICSI, debido a que entre las limitaciones del análisis seminal ${ }^{5}$ está la imposibilidad de evaluar el proceso de capacitación de los espermatozoides en el tracto reproductivo femenino, la adquisición de las proteínas de la membrana plasmática que se requieren para la unión, la reacción acrosomal, la penetración de la zona pelúcida y la capacidad de fecundar el oocito. En algunos estudios, se ha demostrado que el 15\% de los hombres diagnosticados como normozoospérmicos de acuerdo a la $\mathrm{OMS}^{3}$ son infértiles, mientras que otros hombres con parámetros anormales son fértiles y logran embarazos de manera natural. ${ }^{4}$ Por lo tanto, una anormalidad en un solo parámetro o en combinación no puede ser diagnóstico de infertilidad masculina.

Así mismo, algunas investigaciones concuerdan con el presente estudio, en las que se afirma, que los parámetros seminales no tienen ningún impacto en los resultados de ICSI. ${ }^{13}$ Sin embargo, otros estudios sugieren que en algunos casos, la tasa de embarazo se ve afectada en muestras teratozoospérmicas $^{14}$ después de usar ICSI. Los datos contradictorios anteriores evidencian la necesidad de un marcador más robusto y específico para medir la subfertilidad masculina. Sin embargo, el espermograma es el estudio más básico disponible para el especialista y por lo tanto, puede usarse como guía para determinar el siguiente paso en el diagnóstico y tratamiento.

Así mismo, varias investigaciones que han evaluado el efecto de algunos parámetros como la concentración de ERO en los resultados de ICSI, concuerdan con lo hallado en este estudio. $^{15}$ Aunque por el contrario, otros autores han observado una asociación negativa entre los niveles de ROS y 
las tasas de fecundación, desarrollo embrionario y embarazo y esos niveles son más altos en el plasma seminal de hombres infértiles en comparación con hombres fértiles. ${ }^{16}$

Las ERO son subproductos normales del metabolismo, y se requieren en pequeñas cantidades para procesos celulares específicos como la capacitación, la reacción acrosomal y la adquisición del estado hiperactivado. Sin embargo, cuando la concentración de ERO es demasiado alta o se supera la capacidad antioxidante se produce un estrés oxidativo, el cual puede afectar la membrana plasmática y la movilidad y se considera como una de las principales causas del daño en el ADN espermático, siendo también, el parámetro más estudiado, debido a que la integridad del ADN es critico para el mantenimiento del potencial reproductivo paterno y el desarrollo embrionario adecuado. ${ }^{17}$ Se ha demostrado que los espermatozoides con un genoma alterado son capaces de fecundar, ${ }^{18}$ planteando inquietudes acerca de la transmisión del material genético anormal a la descendencia, ya sea durante la concepción natural o mediante el uso de un tratamiento de reproducción asistida. Adicionalmente se conoce que este daño está relacionado con movilidad y morfología anormales pero también se presenta en muestras de semen de hombres infértiles con parámetros seminales normales.

De acuerdo a lo anterior, Ioannou y col., (2016), resaltaron en su trabajo la importancia de la integridad de la cromatina en el establecimiento y mantenimiento de un embarazo viable. ${ }^{19}$ Avendaño y Oehninger (2011), afirmaron que un alto índice de fragmentación puede estar asociado negativamente con la calidad del embrión y la probabilidad de embarazo. ${ }^{20}$ En este sentido, Simon y col., (2014) demostraron que el daño en el ADN espermático disminuye significativamente el porcentaje de embriones de buena calidad de día 3 y de día $5 .{ }^{17}$ Así mismo, parece ser un factor contribuyente en el riesgo de la pérdida de embarazo y en los abortos recurrentes. ${ }^{12,21}$

Varios estudios han demostrado su utilidad clínica en la evaluación de la fertilidad masculina en relación a la fecundación, el desarrollo embrionario a blastocisto y el embarazo. 22,23 Sin embargo, otros autores afirman que los espermatozoides con alteraciones en su ADN pueden fecundar con éxito oocitos a través de FIV e ICSI y que no existe una relación consistente entre el daño en el ADN y el desarrollo embrionario. ${ }^{24}$ Nuñez-Calonge y col., (2012), no observaron diferencias estadísticamente significativas entre los grupos de parejas que logran o no un embarazo, con respecto a la tasa de fecundación y desarrollo embrionario. ${ }^{25}$

Todo lo anterior, soporta los resultados encontrados en este estudio y por lo tanto, el análisis de la integridad del ADN no fue suficiente para discriminar de forma confiable, como una prueba diagnostica debe hacer, entre las parejas que pueden o no conseguir un embarazo. En este sentido, Simon y col., (2011) concluyeron que el semen preparado por gradientes de densidad y el uso posterior en ICSI, tiene un bajo poder predictivo. ${ }^{26}$ Eso puede deberse a que la selección por gradientes de densidad reduce considerablemente la población de espermatozoides con daño ${ }^{27}$, y la posterior selección al momento de hacer ICSI también contribuye, debido a que se plantea la hipótesis de que los espermatozoides móviles y morfológicamente normales tienen un daño bajo en el ADN.

En el presente trabajo se encontró una diferencia significativa en la tasa de embarazo entre las pacientes con oocitos propios y donados $(\mathrm{p}<0.0001)$, pero no se obtuvo ninguna relación entre la fragmentación del ADN espermático y los resultados de ICSI. Esa diferencia se debe probablemente a la capacidad de reparación del daño que posee el oocito humano. Cozzubbo et al y col., (2014) encontraron que los oocitos de mujeres jóvenes tienen la capacidad de reparar el ADN espermático hasta en un $40 \%$, mientras que los oocitos de mujeres mayores son más sensibles. ${ }^{10}$ La reparación de ese daño, depende de la edad de la mujer, el ambiente ovárico y el tipo de infertilidad, las cuales son variables que no afectan usando oocitos donados. ${ }^{28}$

Así mismo, Seli y col., (2004), encontraron que el efecto mitigador del oocito sobre el daño se ve alterado con el aumento de la edad, ya que hallaron una relación entre el daño del ADN paterno y una baja formación de blastocistos en donde la edad de la mujer era de aproximadamente 35 años, ${ }^{29}$ lo que concuerda con este estudio, la media de la edad de las mujeres que usaron sus propios oocitos fue de 35 años. Meseguer et al. y col., (2008), afirman que usando oocitos propios, por cada aumento del $10 \%$ en la fragmentación del ADN espermático, la probabilidad de no embarazo aumentó en un $1,31 .{ }^{30}$

Incluso, algunas investigaciones sugieren que la reparación del daño también ocurre en el cigoto dependiendo enteramente de los ARNm y las proteínas maternas depositados y almacenados en el oocito antes de la ovulación. ${ }^{28}$ Por el contrario, si el oocito no es capaz de reparar el daño, algunos estudios sugieren que ese daño en el ADN espermático se expresa durante y después de la implantación conocido como efecto paterno tardío, presentándose abortos espontáneos. ${ }^{28}$

Finalmente, el estudio de la infertilidad masculina presenta un problema clínico debido a que tanto el hombre como la mujer, contribuyen independientemente a la fertilidad de la pareja. Sin embargo, las investigaciones sugieren que el factor femenino es muy importante para lograr un embarazo tanto natural como obtenido por tratamientos de reproducción asistida, hasta el punto de obviar el efecto de un factor masculino.

En conclusión, en este estudio se encontró que no existe una correlación entre los parámetros tanto convencionales como funcionales con respecto a los resultados de ICSI, debido al efecto del uso de gradientes de densidad en la selección espermática y a la suficiencia de la ICSI como técnica de fecundación. También, se debe a la capacidad de los oocitos de mujeres jóvenes de reparar el daño del ADN presente en los espermatozoides, así como en el cigoto o en el embrión, y/o a la expresión de ese daño en el desarrollo embrionario tardío que afecta la implantación. No obstante, la reproducción es un proceso complejo, potenciado por factores extrínsecos, como los protocolos de estimulación y los medios de cultivo, lo cual hace difícil identificar marcadores que aseguren un resultado exitoso. Adicionalmente, el factor femenino es determinante 
para permitir la fecundación, el desarrollo embrionario y el embarazo en los tratamientos de reproducción asistida e incluso de manera natural.

\section{Responsabilidades Éticas}

Protección de personas y animales. Los autores declaran que para esta investigación no se han realizado experimentos en seres humanos ni en animales.

Confidencialidad de los datos. Los autores declaran que en este artículo no aparecen datos de pacientes.

Derecho a la privacidad y consentimiento informado. LoS autores han obtenido el consentimiento informado de los pacientes y/o sujetos referidos en el artículo. Este documento obra en poder del autor de correspondencia.

\section{Conflicto de intereses}

Los autores declaran no tener ningún conflicto de intereses.

\section{Referencias}

1 Kumar N, Singh AK. Trends of male factor infertility, an important cause of infertility: A review of literature. J Hum Reprod Sci 2015; 8(04):191-196

2 Cardona Maya W. Manual de procesamiento de semen humano de la Organización Mundial de la Salud-2010. Actas Urol Esp. Elsevier 2010;34(07):577-578

3 WHO. WHO laboratory manual for the Examination and processing of human semen. 5th ed. WHO Library; 2010

4 de los Ríos J, Cardona WD, Berdugo JA, et al. Los valores espermáticos de 113 individuos con fertilidad reciente no mostraron correlación con los parámetros establecidos por la OMS. Arch Esp Urol 2004;57(02):147-152

5 Lewis SEM. Is sperm evaluation useful in predicting human fertility? Reproduction 2007;134:31-40

6 Samplaski MK, Agarwal A, Sharma R, Sabanegh E. New generation of diagnostic tests for infertility: review of specialized semen tests. Int J Urol 2010;17(10):839-847

7 Cardona Maya WD, Berdugo Gutiérrez JA, de los Ríos J, Cadavid Jaramillo AP. Functional evaluation of sperm in Colombian fertile men. Arch Esp Urol 2007;60(07):827-831

8 Neri QV, Lee B, Rosenwaks Z, Machaca K, Palermo GD. Understanding fertilization through intracytoplasmic sperm injection (ICSI). Cell Calcium 2014;55(01):24-37

9 Mayorga-Torres BJM, Cardona-Maya W, Cadavid Á, Camargo M. Evaluación de los parámetros funcionales espermáticos en individuos infértiles normozooespérmicos. Actas Urol Esp 2013; 37(04):221-227

10 Cozzubbo T, Neri QV, Rosenwaks Z, Palermo GD. To what extent can oocytes repair sperm DNA fragmentation? Fertil Steril 2014; 102(03):e61

11 Evenson DP, Larson KL, Jost LK. Sperm chromatin structure assay: its clinical use for detecting sperm DNA fragmentation in male infertility and comparisons with other techniques. J Androl 2002; 23(01):25-43

12 Gil-Villa AM, Cardona-Maya W, Agarwal A, Sharma R, Cadavid A. Assessment of sperm factors possibly involved in early recurrent pregnancy loss. Fertil Steril 2010;94(04):1465-1472

13 Pereira N, Neri QV, Lekovich JP, Spandorfer SD, Palermo GD, Rosenwaks Z. Outcomes of intracytoplasmic sperm injection cycles for complete teratozoospermia: A case-control study Using Paired Sibling Oocytes. BioMed Res Int 2015;2015:470819
14 De Vos A, Van De Velde H, Joris H, Verheyen G, Devroey P, Van Steirteghem A. Influence of individual sperm morphology on fertilization, embryo morphology, and pregnancy outcome of intracytoplasmic sperm injection. Fertil Steril 2003;79(01): 42-48

15 Pujol A, Obradors A, Esteo E, et al. Oxidative stress level in fresh ejaculate is not related to semen parameters or to pregnancy rates in cycles with donor oocytes. J Assist Reprod Genet 2016;33(04): 529-534

16 Padron OF, Brackett NL, Sharma RK, Lynne CM, Thomas AJ Jr, Agarwal A. Seminal reactive oxygen species and sperm motility and morphology in men with spinal cord injury. Fertil Steril 1997; 67(06):1115-1120

17 Simon L, Murphy K, Shamsi MB, et al. Paternal influence of sperm DNA integrity on early embryonic development. Hum Reprod 2014;29(11):2402-2412

18 Yamauchi Y, Riel JM, Ward MA. Paternal DNA damage resulting from various sperm treatments persists after fertilization and is similar before and after DNA replication. J Androl 2012;33(02): 229-238

19 Ioannou D, Miller D, Griffin DK, Tempest HG. Impact of sperm DNA chromatin in the clinic. J Assist Reprod Genet 2016;33(02): 157-166

20 Avendaño C, Oehninger S. DNA fragmentation in morphologically normal spermatozoa: how much should we be concerned in the ICSI era? J Androl 2011;32(04):356-363

21 Gil-Villa AM, Cardona-Maya W, Agarwal A, Sharma R, Cadavid A. Role of male factor in early recurrent embryo loss: do antioxidants have any effect? Fertil Steril 2009;92(02): 565-571

22 Spanò M, Bonde JP, Hjøllund HI, Kolstad HA, Cordelli E, Leter G; The Danish First Pregnancy Planner Study Team. Sperm chromatin damage impairs human fertility. Fertil Steril 2000;73 (01):43-50

23 Virro MR, Larson-Cook KL, Evenson DP. Sperm chromatin structure assay (SCSA) parameters are related to fertilization, blastocyst development, and ongoing pregnancy in in vitro fertilization and intracytoplasmic sperm injection cycles. Fertil Steril 2004;81(05):1289-1295

24 Zini A, Jamal W, Cowan L, Al-Hathal N. Is sperm DNA damage associated with IVF embryo quality? A systematic review. J Assist Reprod Genet 2011;28(05):391-397

25 Nuñez-Calonge R, Caballero P, López-Fernández C, et al. An improved experimental model for understanding the impact of sperm DNA fragmentation on human pregnancy following ICSI. Reprod Sci 2012;19(11):1163-1168

26 Simon L, Castillo J, Oliva R, Lewis SEM. Relationships between human sperm protamines, DNA damage and assisted reproduction outcomes. Reprod Biomed Online 2011;23(06): 724-734

27 Rougier N, Uriondo H, Papier S, Checa MA, Sueldo C, Alvarez Sedó C. Changes in DNA fragmentation during sperm preparation for intracytoplasmic sperm injection over time. Fertil Steril 2013;100 (01):69-74

28 González-Marín C, Gosálvez J, Roy R. Types, causes, detection and repair of DNA fragmentation in animal and human sperm cells. Int J Mol Sci 2012;13(11):14026-14052

29 Seli E, Gardner DK, Schoolcraft WB, Moffatt O, Sakkas D. Extent of nuclear DNA damage in ejaculated spermatozoa impacts on blastocyst development after in vitro fertilization. Fertil Steril 2004;82(02):378-383

30 Meseguer M, Martínez-Conejero JA, O'Connor JE, Pellicer A, Remohí J, Garrido N. The significance of sperm DNA oxidation in embryo development and reproductive outcome in an oocyte donation program: a new model to study a male infertility prognostic factor. Fertil Steril 2008;89(05):1191-1199 